\title{
A Portfolio Policy Package to Reduce Greenhouse Gas Emissions
}

\author{
John Freebairn \\ Department of Economics, University of Melbourne, Parkville 3010, Australia; j.freebairn@unimelb.edu.au
}

Received: 25 February 2020; Accepted: 27 March 2020; Published: 30 March 2020

\begin{abstract}
Arguments for a portfolio of price, regulation and subsidy policy interventions to reduce the production and consumption of greenhouse gas emissions are presented. The operation and effects of each intervention are described and compared. A combination of different sets of market failures across the many potential decision changes available to producers and consumers to reduce emissions and different properties of the mitigation instruments support a portfolio approach to reduce emissions at a low cost.
\end{abstract}

Keywords: greenhouse gas emissions; pollution taxes; regulations; subsidies

\section{Introduction}

Recognition that the global accumulation of greenhouse gas emissions likely will result in climate change, and then future additional costs of adaptation to climate change, has induced most governments individually and collectively under the guise of the United Nations Convention on Climate Change (UNCCC) to implement economic policies to reduce emissions. Proposed and implemented mitigation policies include: a price per unit of pollution using an emissions or carbon tax, or an emissions trading scheme; regulations such as renewable energy targets, energy efficient vehicles, and restrictions on land clearing; and subsidies including for renewable energy, reafforestation and research and development (R\&D).

This paper argues for a portfolio of the different mitigation instruments to induce decision changes to reduce emissions at a lower cost. Effective policy promotes decision changes by the producers of emissions and importantly also decision changes by business and household buyers on their consumption choices of goods and services involving inputs of the emissions-generating products. In addition to intervention to correct for the pollution external cost market failure, there are other market failures. Other market failures include: the external benefits of $R \& D$ and learning-by-doing in the development and adoption of lower pollution decision options; lack of information and information asymmetries; inertia and other behaviour economic concerns resulting in no or muted decision changes in response to changes in price signals for many business and household decisions; and required complementary infrastructure investments with economies of scale and some public good properties. Differences in the relative applicability and simplicity of the policy interventions to different sets of pollution reduction decisions are also relevant. As argued by Grubb et al. [1], Lehmann [2] and others, the combination of multiple objectives and market failures with different properties of the different policy intervention options point to a package or portfolio of the policy instruments.

The operation of, and the market effects of, the price, regulation and subsidy interventions to reduce emissions are described across different categories of production and consumption decision choice options to reduce emissions. Pros and cons of the different interventions across different categories of decision change options are assessed in terms of reducing pollution at the lowest cost, simplicity and operating costs, and redistribution and equity changes relative to the no-policy intervention scenario. 
The remainder of the article is organised as follows. Section 2 provides a background and context picture of the multitude of potential decision changes to reduce emissions and the cost ranking of the potential decision changes via a marginal abatement cost function. The operation of, economic effects of, and comparative pros and cons of the price, regulation and subsidy policy intervention options are presented in Sections 3-5. The final section draws together the relative merits of the different mitigation policy interventions for a portfolio policy package to meet an emissions reduction target.

\section{Decision Changes to Reduce Emissions}

Decisions to reduce greenhouse gas emissions can be considered under four categories, namely the producers of pollution, the consumption of polluting products, sequestration, and technological change. Many key production methods in the economy involve the output of emissions as a by-product of the production process. Examples include the combustion of fossil fuels in the generation of electricity and transport. Different production methods involve different pollution intensities, for example coal, gas and nuclear electricity generation. Until recent times, for most producers, the emissions were dumped for free with no concern for the social costs of future climate change across the globe.

Table 1 reports the main industry categories or sources of production of greenhouse gas emissions across the globe. The combustion of fossil fuels account for over two-thirds of total emissions as by-products of the generation of electricity, transport, industrial processes including metal refining and cement manufacture, and the production of heat and stationary energy in businesses and homes. Agricultural production, including ruminant animals, deforestation and other land use decisions, account for over $20 \%$ of total annual emissions. Fugitive emissions are associated with the extraction and transport of fossil fuels. Much waste disposal generates emissions. The relative importance of each sector in aggregate emissions varies from one country to another.

Table 1. Annual global greenhouse gas emissions by sector.

\begin{tabular}{cc}
\hline Sector & Percentage Share \\
\hline Electricity power & 25.6 \\
Industrial processes & 15.9 \\
Transport fuels & 13.2 \\
Land use and biomass burning & 12.1 \\
Agricultural production & 11.6 \\
Fossil fuel retrieved, processed and transport & 10.5 \\
Resident, commercial and other & 7.5 \\
Waste disposal & 3.1 \\
\hline
\end{tabular}

Source: International Panel on Climate Change (IPCC) [3].

A second category of decisions to reduce pollution includes business decisions for the purchase of intermediate production inputs and household decisions for purchases of final consumer goods and services which require some of the emissions-producing products as inputs. Often, business and household purchase decisions include options to use less electricity- and transport-intensive production methods, such as more energy efficient machinery and household appliances. Or, households can purchase less electricity- and transport-intensive mixes of goods and services, such as temperature setting and transport mode and distance. Changes in these demand decision choices to less use of electricity, transport and other pollution generating inputs indirectly reduce aggregate emissions. Most businesses and households have available many decision options via their consumption choices to indirectly reduce emissions. Many of these consumption or buyer choice options are among the lower cost ones to reduce emissions.

Decision options to capture and store emissions represents a third category of decision choices. Examples include carbon capture and storage, changes in land use, and purchases of offsets.

To add to these static or current available decision choice options to reduce emissions, decisions to invest in R\&D and other forms of technology development, and then ease of adoption, add new 
and lower cost decision options to reduce emissions over time. Technology advances likely are available across the production, consumption and sequestration categories of decisions. Additional and redirected investments in infrastructure with characteristics of economies of scale and public good spill over benefits either provided directly by governments or involving government regulation often will be complementary components of a reform package to induce and support lower emissions choice decisions by businesses and households [1].

The almost unlimited number of potential decision changes to directly and indirectly reduce greenhouse gas emissions, together with the responsibility for these decisions by most businesses and households throughout the economy, and governments, sets a challenge for mitigation policy making. Further, most of the information about the different choice options, and especially of their relative costs, is private and not readily available to governments.

One way of aggregating the available decision options to reduce greenhouse gas emissions is the marginal abatement cost (MAC) function. As shown in Figure 1, a MAC ranks the different decision options to reduce emissions from the lowest cost option to the highest cost in the form

$$
\mathrm{Ci}=\mathrm{f}(\mathrm{Q} ; \mathrm{Z})
$$

where $\mathrm{Ci}$ is the marginal cost in $\$$ per tonne of $\mathrm{CO}_{2}$-e reduction, $\mathrm{Q}$ is the reduction in emissions relative to the status quo or current set of choices which generate $\mathrm{Qb}$ emissions, and $\mathrm{Z}$ is a set of function shift variables such as technology, structure of the economy and economic output. Gillingham and Stock [4] provided a recent discussion of the MAC.

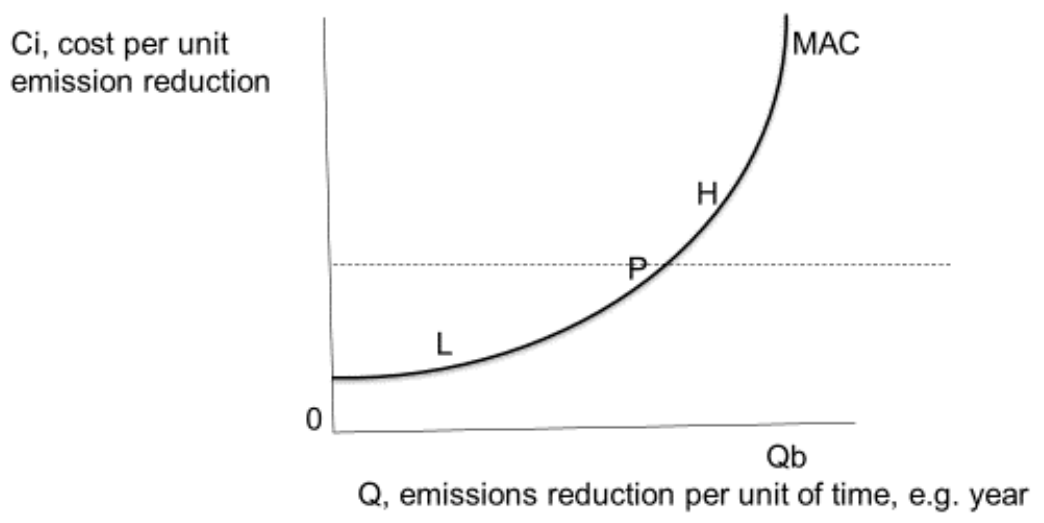

Figure 1. Marginal abatement cost function (MAC).

There is limited information about the details of the MAC, other than that it is a convex function and that production and consumption decision options are included in both the lower and higher cost choice options. Gillingham and Stock [4] reviewed a very wide range of different available estimates of the MAC.

An interesting area of conflicting views concerns whether the MAC is always positive, as illustrated in Figure 1. Most economists argue that the MAC is strictly positive. That is, current decisions and the resulting greenhouse gas emissions are regarded as the best decisions for businesses and households. Alternative decisions with less emissions are less satisfactory and therefore an additional cost. Some reported engineering studies estimate that there are some "free lunch" or "no regrets" decision choices which would both reduce emissions and improve business profits or household wellbeing; that is, the MAC is negative for some decisions. Common examples include more energy efficient lighting and household appliances. Such decisions would be consistent to some economists with asymmetric information and behaviour economics ideas of limited decision-making time and effort, present value biases, and inertia and current decision choice preferences.

Clearly there is much uncertainty about the parameters of the MAC. Most decision options to reduce emissions have not being implemented. Individual businesses and households across the 
country face different circumstances which influence the decision change options to directly or indirectly reduce pollution, and their relative costs. Even for a specific and narrow set of decisions, the additional costs can vary over a wide range across different decision makers and circumstances. For example, the cost of wind power to replace a coal generator varies widely across locations depending on the strength and frequency of wind, costs of additional transmission lines, available construction expertise and costs, thermal efficiency and maintenance status of the coal generator, and so forth.

For any country or sector, the MAC will shift over time. R\&D, learning-by-doing and other sources of new information on lower cost decision options will flatten the curve over time. Faster economic growth will shift the MAC outwards. Changes of output prices and input costs cause shifts of the MAC over time.

\section{A Price on Emissions}

Stemming from Pigou [5], and a recent review by Williams [6], for most economists the first-best policy intervention to reduce pollution, including greenhouse gas emissions, is to impose a price or cost per unit pollution produced. The price on pollution internalises the external costs of the emissions on future climate change. Ideally, the emissions price would raise private costs so that the marginal private cost including the emissions price equates with social costs which includes the climate change costs. Most of the additional cost of pollution payment initially levied on producers is passed forward to business and household consumers as higher prices. Via these market responses, business and household buyers of the associated products face higher relative prices. The changed relative market prices provide incentives for all in the economy to draw on their private-held information and specific circumstances to change decision choices on production, consumption and sequestration, and to a lesser extent R\&D, to less polluting ones.

The emissions price can be implemented as a charge per unit of pollution, often termed a carbon tax or an emissions tax, or via an emissions trading scheme (ETS). An ETS replaces the current arrangement where emissions can be dumped for free with a required property right to pollute. The agreed limited quantity of pollution property rights is less than the current pollution quantity, and an invented market for the limited quantity of property rights, where the rights now have a scarcity value, establishes a price per unit pollution. A carbon or emissions tax has government set the price and with the advantage of price information and stability, while market decisions choose the quantity pollution reduction. By contrast, with an ETS, the government determines the quantity pollution reduction, and the market decisions determine the price and with observed price variation over time. As discussed by Weitzman [7] and Nordhaus [8], the relative merits of a tax and an ETS remains a lively and ambiguous debate.

Redistribution effects of a price on emissions point to a policy package which would recycle most of the government revenue windfall to households. While producers of emissions initially pay the price on pollution, once the market adjusts to the extra production costs and higher consumer prices, households bear most of the economic cost of the pollution as higher relative prices for more pollution intensive goods and services. Across all household purchases, the price on emissions increases the overall cost of living as measured, for example, by an increase in the consumer price index (CPI). Recycling the government revenue windfall to households as higher social security payments and lower income taxes can roughly restore the initial purchasing power capacity and equity position, but with higher relative prices for more pollution intensive goods and services.

Also, the adverse interaction effect of the higher cost of living caused by the price on pollution increasing the tax distortion and tax efficiency costs of pre-existing income and general consumption taxes can be largely offset by recycling the government revenue windfall as lower pre-existing taxes $[6,9]$.

If a country initiates a higher price on emissions than its trading partners, some have proposed as an interim policy recycling some of the revenue gain as an offset for the additional cost born by energy intensive trade exposed industries (including Garnaut, [10]). 
Positive arguments for placing a price on producers of greenhouse gas emissions to reduce pollution are: the intervention provides incentives to reduce pollution at a lower cost by drawing on privately held information by businesses and households across the economy; and, provided the government revenue is recycled to households, most of the redistribution effects and adverse aggravated distortion effects of current general taxes can be nullified. In the context of the MAC of Figure 1, a common price on a comprehensive base of emissions raises the relative prices of different goods and services, and different production methods, roughly in proportion to their pollution intensity as represented along the MAC function. Where decision changes to reduce pollution are less than the price, a lower pollution option is chosen by maximising businesses and households; where the decision change option is more expensive, the choice remains to pollute and pay the tax.

However, there are other market failures and some practical limitations to the price intervention instrument. Using the categories of production of greenhouse gas emissions illustrated in Table 1, while a base for imposing a price on pollution is readily implemented with available information for most items, there are important exceptions. Tax and ETS schemes implemented so far have excluded up to a half or more of emissions. For electricity generators and most large manufacturers with pollution by-products, there are readily available direct measures of the quantity of emissions. Similar data are available for large businesses where waste disposal and fugitive emissions are important. In the case of petroleum and gas products used for transport, heating and other uses, current measures of quantity of product sold by a few refineries and importers times the highly correlated emissions per unit product at point of combustion can be used as a base for the emissions price.

More problematic is a suitable base to impose an emissions price on agricultural production, many land use decisions, and pollution by small businesses. Direct measures of these emissions are difficult and expensive; easier to measure inputs, outputs and methods of production have low correlations with the emission quantity. Often there are debates about the appropriate proxy measure of emissions, for example for agriculture [11]. There are problems in assessing the additionality of emissions reduction for land management and sequestration. Practical reality is that under available information a simple and low operating cost base for placing a price on greenhouse gas emissions is not available for about $20 \%$ of global emissions.

The higher costs of the more pollution-intensive products and production methods resulting from the implementation of a price on emissions augment the incentives and rewards for the allocation of additional funds to R\&D, experimentation and information search for lower cost decision options. However, the price on emissions alone does not include the external benefits of these individual business decisions. That is, these external benefits are a different form of market failure to be more directly addressed by other policy interventions.

A legitimate question of the effectiveness of placing a price on polluters to reduce greenhouse gas emissions concerns the assumption of rational firms and households changing their decisions in response to the changes in relative prices. The question is related to the "no regrets" decision options included in many estimated MAC functions prepared by engineers. For some decisions, and more so for longer-life investments, buyers lack information about the decision options and their relative pros and cons. Government provision of information and education can reduce some of the information gap. Behaviour economics models of bounded rationality, the use of high and inconsistent time preference rates in making investment decisions, decision inertia and reliance on habit persistence purchases can result in muted or even no decision changes in response to the changes in relative prices. Examples of such decision failures include delays in replacing light bulbs, vehicles and household appliances with more energy efficient, lower pollution and lower average long run cost options, and better insulation of buildings. Grubb et al. [1] and Gerarden et al. [12] provide a review of the issues and diverse available estimates of their importance. Shogren and Taylor [13] provide a sceptical review. Many of these missed decision changes are among the lower cost ones on the MAC function.

Confidence about the future path of the emissions price, and stability around that path over time, are important to induce the necessary longer life investment decisions to reduce emissions. The 
EU experience to date of volatile permit prices is a warning regarding practical challenges to the effectiveness of the price intervention to reduce emissions.

The conventional economics textbook appeal of imposing an emissions price, either by a tax or an ETS, should be a major component in a policy package for those producers of pollution with an available and easy to measure tax base. However, there are important categories of pollution with difficult to measure bases. There are other decision areas where other forms of market failure are important. These realities provide a necessary condition, but so far not a sufficient condition, for other policy interventions as complementary measures to the price instrument of a policy portfolio.

\section{Regulations}

Regulated changes to business and household decisions have been an important component, and in some cases the dominant intervention, of government policies to date to reduce greenhouse gas emissions, and other forms of pollution. The regulations require decision changes to less polluting but more costly methods of production, consumption choices, and sequestration. With some important decision area exceptions, conventional economic analysis points to significant disadvantages of the regulatory strategy.

Examples of regulations for less pollution production include a minimum share of renewable electricity generation, restrictions on new coal-fired generators or limits on the share of fossil fuel electricity generated, restrictions on land clearing and on methods of waste disposal. Most of the additional cost of the regulated production decision changes are passed forward to buyers as higher product prices. In turn, these higher product prices provide incentives for businesses and households to choose less pollution-intensive consumption decision options, and for some to choose a sequestration decision option. These additional indirect pollution reduction effects of regulations on production are similar to those driven with the emissions price intervention.

Alternatively, or in addition, regulations can be directed to change consumption decisions to less emission-intensive options. Examples include energy efficiency standards for motor vehicles and household appliances, required home insulation, required replacement of incandescent with fluorescent light bulbs, and restrict travel by air and motor vehicles. These regulated consumption decision changes reduce the demand for the pollution products and indirectly reduce emissions.

Against the context of the very large numbers of potential decision changes to reduce greenhouse gas emissions, the diverse range of additional costs per unit pollution reduction across the different regulated decision changes, and the lack of government information about the relative merits of the many decision options discussed in Section 2 above, as a general outcome regulations are a less cost effective way to reduce emissions than an emissions price. In practice, some government-chosen regulated decision changes are likely to have relatively high costs, and some decision changes with relatively low costs are not regulated or too lightly restricted. In the context of the MAC of Figure 1, some high-cost regulations are at $\mathrm{H}$ and some low cost regulations at $\mathrm{L}$ are not implemented; by contrast, an emissions price of $\mathrm{P}$ would induce decision changes $\mathrm{L}$ but not decisions $\mathrm{H}$. Studies reviewed by Goulder and Parry [14] indicated that costs per unit emission reduction via regulations are about double those for a price intervention.

Consider some examples of how regulations often choose more costly ways to reduce pollution. A renewable energy target for the minimum share of renewables in electricity generation implicitly assumes increasing the share of renewables is the only way to reduce emissions. It rules out other potentially lower cost ways to meet a reduction in emissions by generators, including replacing brown coal with black coal, replacing coal with gas, investment to increase the thermal efficiency of fossil fuel generators, or carbon capture and storage. Energy efficiency targets for motor vehicles, business equipment, and household appliances almost certainly will not be chosen at levels which equate the MAC across motor vehicles, equipment and appliances, and then different models within each of these categories. Further, over time, new technology and information will change the relative cost rankings of the regulated decision changes by MAC across the very large number of different choice categories. 
A second disadvantage of regulations relative to a price on pollution to reduce emissions is that regulations provide no government revenue windfall. Both intervention options require the choice of more expensive choice options. Most of the higher costs are passed forward to household consumers as higher prices. For both the price and regulation policy interventions, the resulting higher average cost of living has equity effects and the loss of effective purchasing capacity aggravates the distortion and efficiency costs of pre-existing income and general consumption taxes. Unlike the government revenue windfall of the price on emissions instrument available to fund compensation, regulations generate no revenue to recycle to households.

An important pro argument for regulations to reduce greenhouse emissions relative to the price on emissions intervention is those decision changes where private sector decision responses to relative price changes are muted by imperfect information and behaviour economics. Arguably for most pollution production decisions, the dominant effects of these decisions for firm profitability, together with competitive forces for survival of the fittest, result in recognition of changes in relative prices and then the adoption of low-cost decision changes to reduce pollution. On the other hand, for many household consumption decision changes involving longer term investments, imperfect information and behaviour economics reasons for sticking with historical and current decision choices can mute responses to relative price changes. For longer term investment decisions, policy uncertainty can contribute to muted responses. These types of decision reactions are a different form of market failure than the greenhouse emissions external cost.

Policy correction for muted decision change responses to relative price changes support direct regulated decision changes. Examples include regulations for such decisions as the energy efficiency of vehicles, household appliances, building structures and insulation. Related experiences across the globe in the use of regulations on petroleum refining, the design of engines to reduce smog and other forms of pollution, and the properties of many household appliances, rather than a pollution tax, provide tangible and effective examples for the consideration of a role for regulations as a complementary component in the policy mix to reduce emissions. In an optimal policy design task, government would consider the contentious trade-off between the limited effects of the price instrument versus the reality of regulations not reflecting least cost emission reduction decisions and no revenue windfall.

The design and implementation of regulations to reduce emissions in land use decisions, agriculture, small businesses and some other pollution production areas face practical implementation challenges much as was discussed for a price intervention. While these areas are also challenging for the use of regulations, in some cases regulations may have an advantage. Regulations on land clearing and some waste disposal decision options are current examples.

\section{Subsidies}

In contrast to the price and regulation policy interventions which impose a penalty or stick on emissions intensive production and consumption choice options, the subsidy intervention provides a benefit or carrot to choose the lower pollution decision options. Examples to reduce the production of pollution include subsidies for investment in renewable energy generation and the sale of electricity generated by nuclear and renewable generators. Subsidies for energy efficient motor vehicles and household appliances and for building insulation seek to shift consumption to less pollution intensive alternatives. Sequestration of emissions can be encouraged by subsidies for reforestation and carbon capture and storage. Another set of subsidies provide grants and tax concessions for R\&D to develop lower cost and lower emissions intensive production methods and consumption choices.

While subsidies for less emissions intensive production and consumption decision choices can have positive first-round effects in reducing pollution, the lower price effects for the subsidised products have adverse second-round effects. In the same way as market reactions pass forward most of the additional costs of a tax or a regulation to buyers as higher prices, most of a subsidy ultimately is passed forward to buyers as lower prices. Lower prices of the subsidised products stimulate additional consumption with a second-round stimulus to consumption with an increase in emissions. To illustrate, 
subsidies for investment in renewable electricity generators provides a first-round incentive to shift a share of the aggregate generation of electricity from fossil fuels to renewables. The lower price for electricity then leads to an increase in aggregate electricity consumption via a larger quantity demand for the lower price pollution intensive goods and services. The second-round effects reduce, and in some cases can fully offset, the first-round reduction in aggregate pollution.

Further, the lower electricity price reduces incentives to change some consumption decision choices which may be among the lower cost ways to reduce emissions.

There are other disadvantages of the subsidy to reduce emissions at lowest cost. Governments face similar challenges discussed in Section 4 for regulations in choosing what production and consumption decision options to subsidise, and then the subsidy rate. Governments do not have access to the privately held information about the required subsidy to select the lower cost per unit pollution reduction options among the millions of potential decision changes available to businesses and households. In practice, some high-cost options will be subsidised, and some low-cost options will not be subsidised. The result is a higher aggregate cost per unit pollution reduction relative to the price intervention. A related challenge is additionality: technical and other changes in economic circumstances may mean some decisions to reduce emissions will be taken without a subsidy, meaning the subsidy, or some of the subsidy, does not change the decision, but incurs additional government expenditure.

Redistribution and equity effects of subsidies to reduce greenhouse gas emissions are different to the effects of the price and regulation interventions. Ultimately, subsidy outlays will be funded by a combination of higher taxes and lower government outlays on health, education and so forth. These budget responses become a loss for households. On average and across all households, the additional budget costs more than offset the lower consumer prices associated with the subsidies.

Subsidies for R\&D and other decision choices to promote technology to find, and then to implement, lower cost emissions mitigation choice options available to businesses and households respond to a different market failure in addition to the pollution external cost, namely external benefits. As argued by Lomborg [15,16], Garnaut [10] and others, new technology for changing circumstances will be vital to reduce emissions, and to lower the costs of emissions reductions. Much basic through to applied research will be required. Given the public good properties of much R\&D, including for ways to reduce emissions, government subsidies to increase $R \& D$ and the pace of technology adoption will enhance society wellbeing. Some would add network externalities and the spill over of future cost savings associated with learning by doing as an additional market failure argument to justify subsidies for early movers to reduce emissions. Government support can include direct funding of R\&D, subsidies and tax concessions for business investors, and the provision of property rights such as patents to enable individual innovating firms to capture a larger share of the society benefits of their investments in innovation.

A critical question is whether $R \& D$ to develop decision options to reduce greenhouse gas emissions has additional claims above the generally available government support for $R \& D$ in general? That is, are there additional market failure reasons, or magnitudes of market failure, associated with the public good and external benefits for R\&D to reduce emissions relative to R\&D for, say, medicine, artificial intelligence and agriculture? Provided an appropriate price is placed on emissions to internalise the pollution cost as presented in Section 3, the argument for special, and addition to, generally available government support for R\&D is not compelling. On the other hand, if for political or other reasons a very low or zero price is placed on emissions, special subsidies for R\&D to develop technologies to improve available producer and consumer decision options to reduce emissions at lower costs becomes a second-best policy intervention.

Subsidies for sequestration, for example for reafforestation and other changes in land use, may be a feasible component of a policy package. In one sense, a subsidy to increase sequestration and reduce aggregate pollution is the other side of a tax or regulations to reduce the negative additional pollution creation decisions associated with some land use decisions discussed in preceding sections. Provided 
the subsidised decision changes are among the lower cost options on the MAC curve, and they are relatively easy to administer, the subsidy intervention is a potential winner.

Grubb et al. [1] argued an important role for government institutional reforms and in some cases subsidies for additional and different investments in infrastructure, including transport and energy transmission networks, to complement price and regulation interventions to reduce emissions. Many of these investments involve market failures associated with economies of scale and market power, and public good benefits. Changes in government policies affecting institutional structures and decisions on infrastructure investments, and direct additional government funded investment, can directly reduce emissions and indirectly support the attraction of private sector decision changes to reduce emissions.

\section{Policy Package}

The very large number of potential decision changes available to most businesses, households, and governments to reduce greenhouse gas emissions provide the reasons for a mix or portfolio of emissions price, regulation and subsidy policy interventions to reduce emissions at lowest cost and to roughly preserve equity. Across the wide array of potential lower pollution decision options, there are different market failures of external costs and external benefits, and there are concerns of muted decision change responses to the different policy interventions. While there can and should be on-going debates about specific details of the appropriate policy package for each country and over time, the general structure of a policy package is as follows.

For a large set of the decisions to reduce greenhouse gas emissions, an emissions price, either a tax or an ETS, with most of the government revenue windfall recycled to households is the dominant policy intervention. Placing a price on the production of emissions seeks to internalise the external cost of pollution. The flow through of the additional production costs changes relative prices for consumers as well as producers. Importantly, the relative price changes provide incentives and rewards to draw on private-held information to find the lower cost pollution reduction decision options. An emissions price is relatively simple to apply and monitor for most decisions, but not all. The simple to apply base includes current measured emission quantities by electricity generators, other large manufacturers, and producers of fugitive and waste emissions. For petroleum and gas products used for transport and heating, the input is easily measured and highly correlated with emissions. Challenging base decision areas include agriculture, other land uses, and small businesses. Recycling the revenue windfall to households can compensate most of the redistribution effects of higher costs driven by the passing forward of the emissions price and to offset the interaction effects of the higher cost of living aggravating the distortion costs of pre-existing income and consumption taxes.

Other forms of market failures and limitations of the application of an emissions price point to including subsidies and regulations as complementary components of the policy package. First, while the price on emissions increases the incentives and rewards for necessary development and adoption of new technology on lower cost decision options to reduce emissions, the R\&D, learning-by-doing and related decisions involve external benefits. At a minimum, a complementary policy intervention requires extension of the current systems of subsidies and property rights to internalise the external benefits of R\&D activities in general, including for medicine, agriculture and manufacturing, to include government and private sector investments for new, modified and lower cost decision choice options to reduce greenhouse gas emissions. New investment in infrastructure, both direct government-funded and privately funded under government regulations, is also required as part of a policy package to reduce emissions at the lowest national cost.

Second, the strong assumptions of rational business profit maximising and of household wellbeing maximising decision responses to changes in relative prices caused by a price intervention policy to reduce emissions are unrealistic for some decisions. Examples include the choices of more energy efficient motor vehicles and household appliances, and building insulation by households, and perhaps also more energy efficient production methods by some businesses. Regulations on businesses 
to meet minimum energy efficiency standards for these products likely will be a complementary policy intervention.

Regulations and subsidies may be simpler and easier to implement and monitor than an emissions price to change some decisions on land management, with examples of restrictions on land clearing and subsidies for reafforestation.

Finding simple to apply and low administration cost policy interventions to change decisions to reduce greenhouse gas emissions by agriculture and other small businesses remains a challenge, including for the price, regulation and subsidy options.

Funding: This research received no external funding.

Acknowledgments: I thank two referees for valuable comments, and accept full responsibility for the final version.

Conflicts of Interest: The author declares no conflict of interest.

\section{References}

1. Grubb, M.; Hourcude, J.; Neuhoff, K. Planetary Economics: Energy, Climate Change and the Three Domains of Sustainable Development; Routledge: New York, NY, USA, 2014.

2. Lehmann, P. Justifying a Policy Mix for Pollution Control: A Review of Economic Literature. J. Econ. Surv. 2012, 26, 71-97. [CrossRef]

3. International Panel on Climate Change (IPPC). Fifth Assessment Report of the Intergovernmental Panel on Climate Change; Cambridge University Press: Cambridge, UK, 2014.

4. Gillingham, K.; Stock, J. The Cost of Reducing Greenhouse Gas Emissions. J. Econ. Perspect. 2018, 32, 53-72. [CrossRef]

5. Pigou, A. The Economics of Welfare; MacMillan: London, UK, 1920.

6. Williams, R. Environmental Taxation. In The Economics of Tax Policy; Auerbach, A., Smetters, K., Eds.; Oxford Scholarship On Line: Oxford, UK, 2017.

7. Weitzman, M. Voting on Prices vs. Quantities in a World Climate Assembly. Res. Econ. 2017, 71, 199-211. [CrossRef]

8. Nordhaus, W. Climate Change: The Ultimate Challenge for Economics. Am. Econ. Rev. 2019, 109, 1991-2014. [CrossRef]

9. Goulder, L. Environmental Taxes and the Double Dividend: A Readers Guide. Int. Tax Public Financ. 1995, 2, 157-183. [CrossRef]

10. Garnaut, R. The Garnaut Climate Change Review: Final Report; Cambridge University Press: Cambridge, $\mathrm{UK}, 2008$.

11. Thamo, T.; Addai, D.; Kragt, M.; Kingwell, R.; Pannell, D.; Robertson, M. What Farmers are Likely to Adopt Joint Venture Farm Business Structures. Aust. J. Agric. Resour. Econ. 2019, 63, 881-896.

12. Gerarden, T.; Newell, R.; Stavins, R. Assessing the Energy-efficiency Gap. J. Econ. Lit. 2017, 55, 1486-1525. [CrossRef]

13. Shogren, J.; Taylor, L. On Behavioral-Environmental Economics. Rev. Environ. Econ. Policy 2008, 2, 26-44. [CrossRef]

14. Goulder, L.; Parry, I. Instrument Choice in Environmental Policy. Rev. Environ. Econ. Policy 2019, 2, 152-174. [CrossRef]

15. Lomborg, B. The Skeptical Environmentalist: Measuring the Real State of the World; Cambridge University Press: Cambridge, UK, 2001.

16. Lomborg, B. Smart Solutions to Climate Change: Comparing Costs and Benefits; Cambridge University Press: Cambridge, UK, 2010.

(C) 2020 by the author. Licensee MDPI, Basel, Switzerland. This article is an open access article distributed under the terms and conditions of the Creative Commons Attribution (CC BY) license (http://creativecommons.org/licenses/by/4.0/). 